\title{
High expression of c-Met and EGFR is associated with poor survival of patients with glottic laryngeal squamous cell carcinoma
}

\author{
MEI JIANG ${ }^{1 *}$, HUI ZHANG ${ }^{1 *}$, HE XIAO $^{1}$, ZHIMIN ZHANG $^{2}$, DAN QUE $^{1}$, JIA LUO $^{1}$, JIAN LI $^{1}$, \\ BIJING MAO ${ }^{1}$, YUANYUAN CHEN ${ }^{1}$, MEILIN LAN $^{1}$, GE WANG $^{1}$ and HUALIANG XIAO ${ }^{3}$ \\ ${ }^{1}$ Cancer Center, Institute of Surgical Research, Daping Hospital, \\ Third Military Medical University, Chongqing 400042; ${ }^{2}$ Department of Oncology, Wuhan General Hospital of \\ Guangzhou Command, People's Liberation Army, Wuhan, Hubei 430070; ${ }^{3}$ Department of Pathology, Institute \\ of Surgical Research, Daping Hospital, Third Military Medical University, Chongqing 400042, P.R. China
}

Received September 28, 2015; Accepted April 21, 2017

DOI: $10.3892 / \mathrm{ol} .2017 .7356$

\begin{abstract}
The present study was undertaken to explore the association between the expression of hepatocyte growth factor receptor (c-Met) and epidermal growth factor receptor (EGFR) with clinicopathological factors and survival status, to obtain prognostic biomarkers in patients with glottis laryngeal squamous cell carcinoma (GLSCC). The expression status of c-Met and EGFR protein was analyzed in 71 archival laryngeal cancer samples by immunohistochemistry. Statistical methods, including univariate and multivariate Cox regression analysis, were used to determine risk factors of progression. In addition, survival analysis was performed by the Kaplan-Meier method. The present study detected positive expression of c-Met and EGFR in 69.0 and $91.5 \%$ of GLSCC samples, respectively. The median disease-free survival (DFS) and overall survival (OS) times of all patients were 42.4 and 81.8 months, respectively, and the 2-year DFS and OS rates were 60.1 and $84.91 \%$, respectively. Univariate Cox regression analysis revealed that patients with high expression of EGFR or c-Met had a predisposition for tumor recurrence. The expression of c-Met expression was significantly associated with that of EGFR $(\mathrm{P}=0.001)$. High expression of $\mathrm{c}-\mathrm{Met}$ or EGFR was associated with shorter DFS and OS times. Findings of the multivariate Cox regression analysis indicated that c-Met-expression may
\end{abstract}

Correspondence to: Dr Ge Wang, Cancer Center, Institute of Surgical Research, Daping Hospital, Third Military Medical University, 10 Changjiang Road, Chongqing 400042, P.R. China E-mail: wangge70@hotmail.com

Dr Hualiang Xiao, Department of Pathology, Institute of Surgical Research, Daping Hospital, Third Military Medical University, 10 Changjiang Road, Chongqing 400042, P.R. China

E-mail: dpbl-xhl@126.com

*Contributed equally

Key words: hepatocellular carcinoma, transcatheter arterial chemoembolization, cluster of differentiation 151, tumor progression be used as an independent predictor of DFS and OS $(\mathrm{P}=0.002$ and $\mathrm{P}=0.008$, respectively). However, EGFR expression was not an independent predictor for DFS and OS $(\mathrm{P}=0.352$ and $\mathrm{P}=0.24$, respectively). The high expression of c-Met and EGFR was associated with poor survival and are important predictors for prognosis of patients with GLSCC.

\section{Introduction}

Laryngeal squamous cell carcinoma (LSCC) is the second most common type of head and neck squamous cell cancer (HNSCC), representing $2.4 \%$ of all cancer cases and $2.1 \%$ of all cancer-associated mortalities worldwide in June 2009 (1). The latest Chinese cancer statistics indicated that an 26,400 novel cancer cases and 14,500 cancer mortalities occurred in China in 2015 (2). Despite significant progress in surgery, radiotherapy and chemotherapy over the last few decades, there has been no improvement in the 5-year survival status of patients with laryngeal cancer (LC), which has remained steady at $70-80 \%$ (3). It was observed that the 3-year disease-free survival (DFS) rate post-surgical intervention was $71.2 \%$, while there was a significant decrease in survival rates for patients with recurrent/metastatic (R/M) LC (4). One of the reasons for the poor survival rates in glottis LSCC (GLSCC) may be due to inadequate tumor profiling using conventional histopathology (4). Thus, it is necessary to elucidate the molecular basis of LC and to detect prognostic biomarkers, which may enable clinicians to improve the management of patients with LSCC.

Epidermal growth factor receptor (EGFR) is a transmembrane glycoprotein. This receptor binds with different types of ligands, which induce receptor homo- and heterodimerization, leading to intrinsic tyrosine kinase activation, and resulting in cell proliferation, apoptosis, differentiation and survival (5). A total of $<90 \%$ of patients with HNSCC express high levels of EGFR, which is associated with poor survival (6). EGFR inhibitors, including cetuximab, have been approved by the Food Drug Administration as monotherapy for R/M HNSCC (7). Several studies have explored the association between EGFR and prognosis. However, the role of EGFR overexpression remains controversial in HNSCCs, including LSCC (8-10). 
Hepatocyte growth factor (HGF) receptor (c-Met) encodes a transmembrane tyrosine kinase. It is known to stimulate cell motility, dissociation of epithelial sheets, invasion of cellular matrix and induction of angiogenesis (11). This receptor was found to be overexpressed in the majority of types of solid tumors (12).

The incidences of overexpression of c-Met in lung, colorectal cancer and renal cell carcinoma are 13.7, 50.0 and $44.8 \%$, respectively, and are strongly associated with poor prognosis (13-15). Overexpression of c-Met has been observed in $50-80 \%$ of HNSCC cases (16-18), with a mutation rate of $14 \%$ (19). Studies have demonstrated that overexpression of c-Met is associated with tumor progression, and is an important treatment target of HNSCC $(16,20,21)$. However, the association between c-Met expression and survival status in glottic LSCC (GLSCC) has been rarely studied (22).

Since there is heterogeneity in results when cancer samples from different sites in the head and neck are used (23-26), analysis was restricted to only GLSCC samples. Association of c-Met and EGFR with clinical factors and survival status has not yet been studied in GLSCC. To the best of our knowledge, this is the first study that investigates the role of EGFR and c-Met in GLSCC. The expression of EGFR and c-Met was assessed in patients with GLSCC, and the expression of EGFR and c-Met was compared with clinical parameters and DFS and overall survival (OS) status. The present study found that high expression of c-Met or EGFR were associated with poor survival and are important predictors for prognosis of patients with GLSCC.

\section{Materials and methods}

Ethics. The experimental protocol was established, according to the ethical guidelines of the Declaration of Helsinki and was approved by the Human Ethics and Protocol Review Committee of the Third Military Medical University (Chongqing, China). Written informed consent was obtained from individual patients in the study. All patients or guardians, subsequent to reading, filled in and signed the consent form and agreed to be involved in the present study.

Patients. The present study included 71 male patients with a diagnosis of GLSCC, only male patients were included as the incidence of GLSCC tends to be higher in males than females (2). These patients were treated at the Third Affiliated Hospital, Third Military Medical University, Chongqing University (Chongqing, China) between December 2006 and December 2011. The median age was 60 years old (range, 39-79 years). The Tumor staging and grading was determined according to the American Joint Committee on Cancer tumor-node-metastasis classification system of 2002 (27) and histological grade was based on the World Health Organization system (Table I). Primary treatment for all 71 patients was surgery, which included 44 cases with post-operation radiotherapy, 7 cases with post-operation concurrent chemoradiotherapy and 20 patients without any post-surgery treatment. There were 39 recurrent cases. The primary endpoint of the study was DFS, and the secondary endpoint was OS.

Immunohistochemistry (IHC). All tissue samples were fixed in $4 \%$ formaldehyde solution at $4^{\circ} \mathrm{C}$ for $24 \mathrm{~h}$, dehydrated with 70,80 and $95 \%$ alcohol, each for $5 \mathrm{~min}$, followed by $100 \%$ alcohol 3 times for $5 \mathrm{~min}$, embedded in paraffin and cut into $3-\mu \mathrm{m}$-thick sections for IHC. Human c-Met polyclonal antibody (catalog no. ZA-0636; Zhong Shan Golden Bridge Biological Technology, Beijing, China) and human EGFR monoclonal antibody (catalog no. ZA-0505; Zhong Shan Golden Bridge Biological Technology) primary antibodies were pre-diluted by the supplier. Immunostaining was achieved by SPlink Detection kit (Biotin-Streptavidin HRP Detection System; catalog no. SP-9001; Zhong Shan Golden Bridge Biological Technology) according to the manufacturer's protocol. Sections were dewaxed in xylene 2 times ( 5 min each) and rehydrated using a descending alcohol series (100\% alcohol 2 times for 3 min each, followed by once with 95, 70 and 50\% alcohol for 3 min each). Subsequently, endogenous peroxidase activity was blocked by incubation with $0.3 \%$ hydrogen peroxide in methanol at room temperature for 10 min to block endogenous peroxidase activity. Sections were incubated with the aforementioned primary antibody overnight at $4^{\circ} \mathrm{C}$ and later sequentially incubated with biotin-labeled goat anti-rabbit IgG and HRP-conjugated streptavidin, pre-diluted by the supplier (Biotin-Streptavidin HRP Detection Systems; catalog no. SP-9001; Zhong Shan Golden Bridge Biological Technology) at room temperature for $1 \mathrm{~h}$. The peroxidase reaction was visualized using 3,3'-Diaminobenzidine (DAB) substrate solution $\left(0.05 \%\right.$ DAB, $0.015 \% \mathrm{H}_{2} \mathrm{O}_{2}$, PBS) for $5 \mathrm{~min}$ at room temperature and the sections were counterstained with hematoxylin. Negative controls were assessed by replacing the primary antibody with PBS.

The expression of EGFR and c-Met was evaluated using immunostaining. The slides were examined by two independent pathologists (Department of Pathology, Institute of Surgical Research, Daping Hospital, Third Military Medical University, Chongqing, China), who had no prior knowledge of the clinical and pathological parameters. The intensity of staining was classified into four grades: No staining, -; definite but weak staining, +; moderate staining, ++; and strong staining, +++ (28). This method has been used and validated previously (29). The proportion of positive cells was counted in five microscopic fields at x400 magnification (range, 0-100\%). The percentage of cells with different staining intensities was determined by visual assessment with light microscopy. The $\mathrm{H}$-score was calculated using the formula $1 \mathrm{x}$ ( $\%$ of weak staining cells) $+2 \mathrm{x}$ ( $\%$ of moderate staining cells) $+3 x$ (\% of strong staining cells; range, $0-300)(30)$.

Statistical analysis. Statistical analyses were performed using SPSS software version 16.0 (SPSS, Inc., Chicago, IL, USA). The $\chi^{2}$ test and Fisher's exact test were used to analyze the association between expression of c-Met and EGFR, and clinicopathological factors. Univariate and multivariate Cox proportional hazards regression models were used to find prognostic factors of DFS and OS. The likelihood ratio test was used to determine if one covariate entered into the regression models is significant. Survival analysis was performed by the Kaplan-Meier method, and the log-rank test was used to compare the survival curves. $\mathrm{P}<0.05$ was considered to indicate a statistically significant difference.

\section{Results}

Association between clinicopathological parameters and expression of EGFR and c-Met proteins in patients with 
Table I. Association between clinicopathological factors and EGFR and c-Met expression.

\begin{tabular}{|c|c|c|c|c|c|c|c|}
\hline \multirow[b]{2}{*}{ Factors } & \multirow[b]{2}{*}{ Number, n (\%) } & \multicolumn{3}{|c|}{ EGFR expression, $\mathrm{n}$} & \multicolumn{3}{|c|}{ c-Met expression, $n$} \\
\hline & & Low & High & P-value & Low & High & P-value ${ }^{a}$ \\
\hline Age & & & & 0.262 & & & $0.034^{\mathrm{a}}$ \\
\hline$\leq 50$ years & $11(15.5)$ & 7 & 4 & & 9 & 2 & \\
\hline$>50$ years & $60(84.5)$ & 24 & 36 & & 25 & 35 & \\
\hline Smoking & & & & 0.841 & & & 0.634 \\
\hline No & $13(18.3)$ & 6 & 7 & & 7 & 6 & \\
\hline Yes & $58(81.7)$ & 25 & 33 & & 27 & 31 & \\
\hline Alcohol use & & & & 0.144 & & & 0.327 \\
\hline No & $46(64.8)$ & 23 & 23 & & 24 & 22 & \\
\hline Yes & $25(35.2)$ & 8 & 17 & & 10 & 15 & \\
\hline Tstage & & & & 0.200 & & & 0.060 \\
\hline $\mathrm{T} 1$ & $12(16.9)$ & 5 & 7 & & 9 & 3 & \\
\hline $\mathrm{T} 2$ & $34(47.9)$ & 11 & 23 & & 12 & 22 & \\
\hline $\mathrm{T} 3$ & $18(25.2)$ & 11 & 7 & & 8 & 10 & \\
\hline $\mathrm{T} 4$ & $7(10.0)$ & 4 & 3 & & 5 & 2 & \\
\hline N stage & & & & 0.368 & & & 1.000 \\
\hline N0 & 65 (91.5) & 27 & 38 & & 32 & 33 & \\
\hline N1 & $5(7.0)$ & 3 & 2 & & 2 & 3 & \\
\hline $\mathrm{N} 2$ & $1(1.5)$ & 1 & 0 & & 0 & 1 & \\
\hline Clinical stage & & & & 0.194 & & & 0.082 \\
\hline I & $10(14.1)$ & 3 & 7 & & 7 & 3 & \\
\hline II & $30(42.2)$ & 10 & 20 & & 10 & 20 & \\
\hline III & $21(29.6)$ & 12 & 9 & & 10 & 11 & \\
\hline IV & $10(14.1)$ & 6 & 4 & & 7 & 3 & \\
\hline Histological grade & & & & 0.525 & & & 0.213 \\
\hline G1 & $26(36.7)$ & 9 & 17 & & 16 & 10 & \\
\hline $\mathrm{G} 2$ & $41(57.7)$ & 20 & 21 & & 17 & 24 & \\
\hline G3 & $4(5.6)$ & 2 & 2 & & 1 & 3 & \\
\hline Recurrence & & & & $0.001^{\mathrm{a}}$ & & & $<0.001^{\mathrm{a}}$ \\
\hline Yes & $39(55.0)$ & 10 & 29 & & 9 & 30 & \\
\hline No & $32(45.0)$ & 21 & 11 & & 25 & 7 & \\
\hline
\end{tabular}

${ }^{\mathrm{a}} \mathrm{P}<0.05$; EGFR, epidermal growth factor receptor; $\mathrm{T}$ stage, tumor stage; $\mathrm{N}$ stage, node stage.

GLSCC. Positive expression (either complete membranous staining or cytoplasmic staining near the cell membrane) of c-Met and EGFR was observed in 69.0 (49/71) and 91.5\% (65/71) cases, respectively (Fig. 1). The median values of H-score of c-Met and EGFR expression were 160 (range, 0-270) and 240 (range, 0-270), respectively. When the H-score in individual subjects was greater than the median value, it was considered to be indicative of a high expression of c-Met and EGFR.

Table I presents the association between c-Met and EGFR expression and clinicopathological factors. High expression of EGFR or c-Met was significantly associated with tumor recurrence in GLSCC ( $\mathrm{P}=0.001$ and $\mathrm{P}<0.001$, respectively). Factors, including old age, advanced $\mathrm{T}$ stages and tumor recurrence, were significantly associated with high expression of c-Met $(\mathrm{P}=0.034, \mathrm{P}=0.06$ and $\mathrm{P}<0.001$, respectively). High expression of EGFR was strongly associated with only tumor recurrence $(\mathrm{P}=0.001)$ and not with other factors. In addition,
Table II. Association between EGFR expression and c-Met expression.

\begin{tabular}{lrrr}
\hline & \multicolumn{2}{c}{ EGFR, $\mathrm{n}$} & \\
\cline { 2 - 3 } Expression & Low & High & P-value \\
\hline c-Met & 22 & 12 & $0.001^{\mathrm{a}}$ \\
Low & 9 & 28 & \\
High & & & \\
\hline
\end{tabular}

${ }^{\mathrm{a}} \mathrm{P}<0.05$; EGFR, epidermal growth factor receptor.

22 patients showed reduced expression of EGFR and c-Met, while high expression of EGFR and c-Met was detected in 28 patients (Table II). These findings suggested that there was 

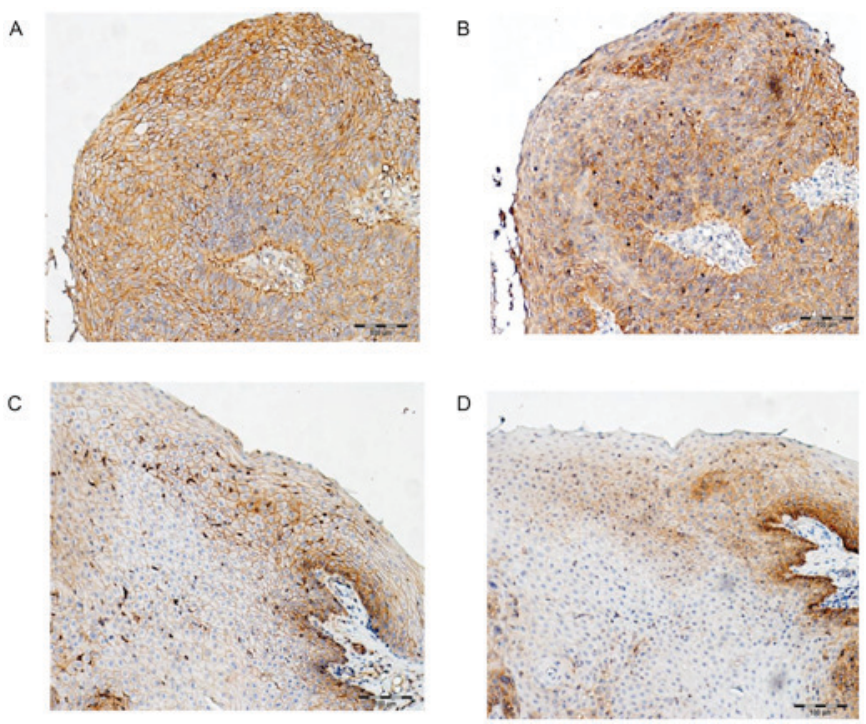

Figure 1. Expression of EGFR and c-Met in membrane and cytoplasm of laryngeal cancer sections; images were captured at x100 magnification. (A) EGFR high-expression with an $\mathrm{H}$-score of 300 , and $100 \%$ cells staining strongly (+++). (B) c-Met high-expression with an H-score of 270 , and $90 \%$ cells staining strongly (+++). (C) EGFR low-expression with an H-score of 120 , and $60 \%$ cells staining moderately (++). (D) c-Met low-expression with an $\mathrm{H}$-score of 80 , and $40 \%$ cells staining moderately (++). EGFR, epidermal growth factor receptor.

a significant positive association between the expression of EGFR and that of $\mathrm{c}-\mathrm{Met}(\mathrm{P}=0.001)$.

Survival analysis. All patients were followed up until mortality or until December 31, 2014. During the follow-up period, 20 patients succumbed due to GLSCC-associated disease, 6 patients were lost to follow-up. A total of 45 patients remain alive as of the last follow-up. The median follow-up time was 43 months (range, 12-96). The median DFS and OS times of all patients were 42.4 and 81.8 months, respectively. The DFS and OS for 1, 2 and 3-years were 75.9,60.1 and 54.2\%, and 95.22, 84.91 and $77.01 \%$, respectively (Fig. 2A and B). Kaplan-Meier survival analysis for DFS revealed that patients with low levels of EGFR expression had a longer DFS time compared with patients with high expression, and the 2-year DFS rates were 69.5 and $51.7 \%$, respectively, in these two groups of patients (log-rank $\chi^{2}=9.708 ; P=0.002$; Fig. 2C). Similarly, the DFS time was longer in patients with low expression of c-Met compared with patients with high expression, and the 2-year DFS rates were 73.5 and $47.3 \%$, respectively $\left(\log\right.$-rank $\chi^{2}=19.526$; $\mathrm{P}<0.001$; Fig. 2D). In addition, the 2 -year OS rate was $89.8 \%$ in patients with low levels of EGFR vs. $79.4 \%$ in patients with high expression (log-rank $\chi^{2}=7.066 ; \mathrm{P}=0.008$; Fig. $2 \mathrm{E}$ ), and the 2-year OS rate was $94.7 \%$ in patients with low level of c-Met vs. $73.1 \%$ in patients with high expression (log-rank $\chi^{2}=12.805$, $\mathrm{P}<0.001$; Fig. 2F).

The patients were categorized into three subgroups: A low-risk group, comprising of patients with low EGFR and c-Met expression; a high-risk group, comprising patients with high EGFR and c-Met expression; and a moderate-risk group, comprised of patients with only one highly-expressed protein (EGFR or c-Met). The 2-year DFS rates in low-, moderateand high-risk groups were $81.8,51.0$ and $47.8 \%$, respectively
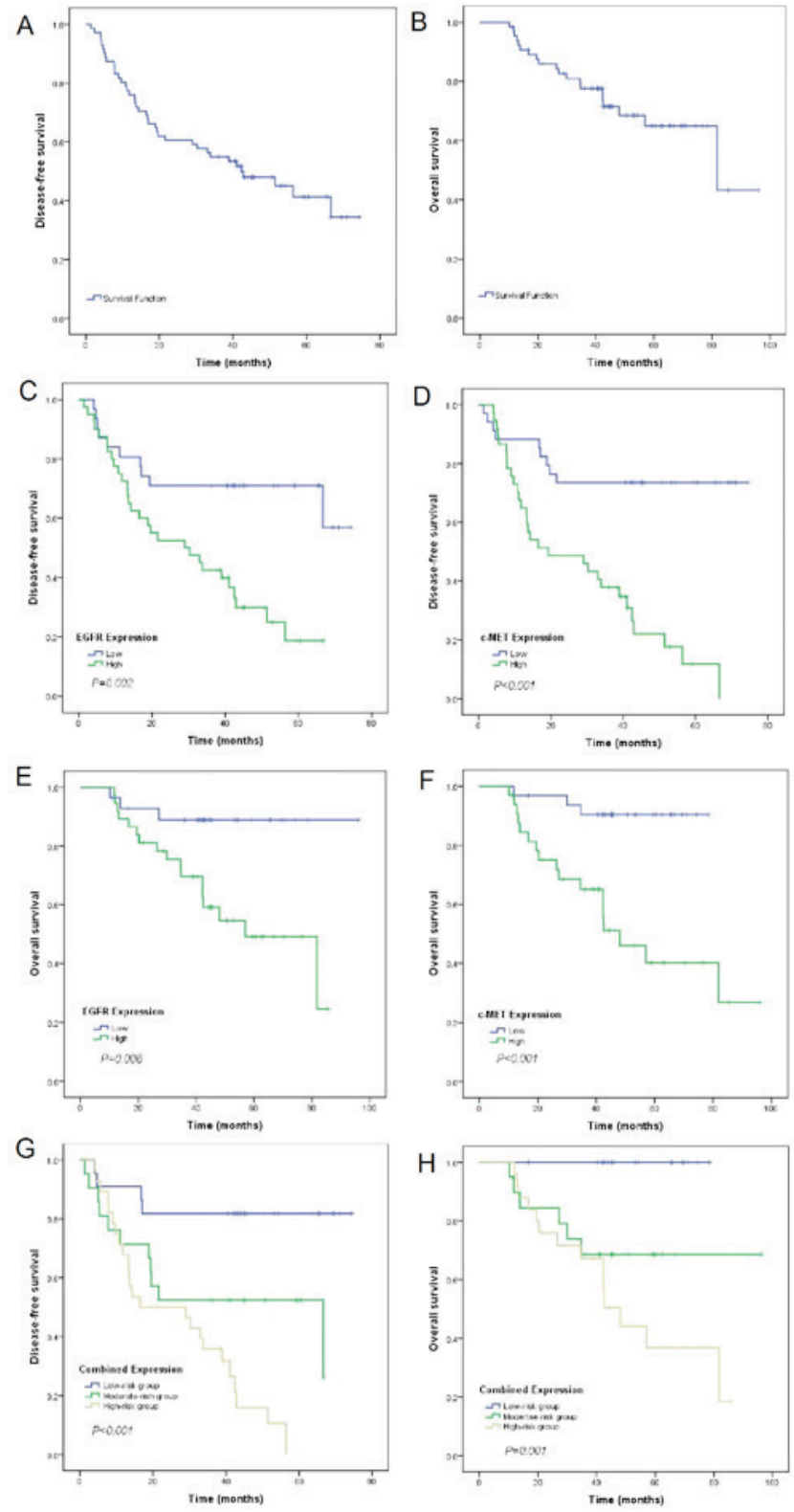

Figure 2. KM curves demonstrated different prognosis between subgroups. (A) Survival analysis of whole population for DFS, (B) Survival analysis of whole population for OS, (C) KM curves of DFS for EGFR low and high expression subgroups, (D) KM curves of FDS for c-MET low and high expression subgroups, (E) KM curves of OS for EGFR low and high expression subgroups, (F) KM curves of OS for c-MET low and high expression subgroups, (G) KM curves of DFS for low, moderate and high risk subgroups, (H) KM curves of OS for low, moderate and high risk subgroups. EGFR, epidermal growth factor receptor; DFS, disease-free survival; OS, overall survival; KM, Kaplan-Meier.

(log-rank, $\chi^{2}=20.214 ; \mathrm{P}<0.001$; Fig. 2G). The 2-year OS rates in low-, moderate- and high-risk groups were 100.0, 80.4 and $73.5 \%$, respectively (log-rank, $\chi^{2}=13.570 ; \mathrm{P}=0.001$; Fig. $2 \mathrm{H}$ ).

Univariate and multivariable analysis of prognostic factors for DFS and OS. Univariate Cox regression analysis showed a significant association of expression of EGFR- and c-Metwith DFS and OS (Tables III and IV). The risk of disease progression was significantly increased in patients with high expression of c-Met or EGFR when compared with those with low expression $(\mathrm{HR}=4.785, \mathrm{P}<0.001 ; \mathrm{HR}=3.028$, 
Table III. Univariate/multivariable analyses of prognosis factors for disease-free survival.

\begin{tabular}{lccccccc}
\hline & \multicolumn{3}{c}{ Univariate } & & \multicolumn{3}{c}{ Multivariable } \\
\cline { 2 - 3 } Factors & $95 \% \mathrm{CI}$ & HR & P-value & & $95 \% \mathrm{CI}$ & HR & P-value \\
\hline Age ( $\leq 50$ vs. $>50)$ & $0.911-9.664$ & 2.967 & 0.071 & & - & - & - \\
Smoking (no vs. yes) & $0.343-1.528$ & 0.724 & 0.396 & & - & - & - \\
Drinking (no vs. yes) & $0.633-2.091$ & 1.151 & 0.645 & & - & - & - \\
T stage (T1/2 vs. T3/4) & $0.480-1.795$ & 0.929 & 0.826 & & - & - & - \\
N stage (N1/2 vs. N0) & $1.251-8.426$ & 3.246 & $0.016^{\mathrm{a}}$ & & $0.993-19.773$ & 4.432 & 0.051 \\
Clinical stage (I/II vs. III/IV) & $0.572-2.041$ & 1.080 & 0.812 & & - & - & - \\
Histological grade (G1 vs. G2/3) & $0.357-1.269$ & 0.674 & 0.222 & & $0.172-0.818$ & 0.376 & 0.014 \\
EGFR expression(high vs. low) & $1.458-6.286$ & 3.028 & $0.003^{\mathrm{a}}$ & & $0.631-3.650$ & 1.518 & 0.352 \\
c-Met expression(high vs. low) & $2.239-10.225$ & 4.785 & $<0.001^{\mathrm{a}}$ & & $1.695-9.678$ & 4.050 & 0.002 \\
\hline
\end{tabular}

${ }^{\mathrm{a}} \mathrm{P}<0.05$; CI, confidence interval; HR, hazard ratio; EGFR, epidermal growth factor receptor; T stage, tumor stage; $\mathrm{N}$ stage, node stage.

Table IV. Univariate/multivariable analyses of prognosis factors for overall survival.

\begin{tabular}{|c|c|c|c|c|c|c|}
\hline \multirow[b]{2}{*}{ Factors } & \multicolumn{3}{|c|}{ Univariate } & \multicolumn{3}{|c|}{ Multivariable } \\
\hline & $95 \% \mathrm{CI}$ & HR & P-value ${ }^{a}$ & $95 \% \mathrm{CI}$ & HR & P-value \\
\hline Age ( $\leq 50$ vs. $>50$ years) & $0.417-7.838$ & 1.809 & 0.428 & - & - & - \\
\hline Smoking (no vs. yes) & $0.159-1.029$ & 0.405 & 0.058 & $0.163-1.654$ & 0.520 & 0.268 \\
\hline Drinking (no vs. yes) & $0.351-2.188$ & 0.876 & 0.777 & - & - & - \\
\hline $\mathrm{T}$ stage (T1/2 vs. T3/4) & $0.554-3.322$ & 1.357 & 0.504 & - & - & - \\
\hline $\mathrm{N}$ stage (N1/2 vs. N0) & $0.602-11.572$ & 2.640 & 0.198 & - & - & - \\
\hline Clinical stage (I/II vs. III/IV) & $0.784-4.756$ & 1.895 & 0.156 & - & - & - \\
\hline Histological grade (G1 vs. G2/3) & $0.288-1.682$ & 0.697 & 0.421 & - & - & - \\
\hline EGFR expression (high vs. low) & $1.333-15.562$ & 4.554 & $0.016^{\mathrm{a}}$ & $0.538-11.909$ & 2.532 & 0.240 \\
\hline c-Met expression (high vs. low) & $2.026-24.026$ & 6.976 & 0.002 & $1.780-45.921$ & 9.040 & 0.008 \\
\hline
\end{tabular}

${ }^{\text {a }} \mathrm{P}<0.05$; CI, confidence interval; HR, hazard ratio; EGFR, epidermal growth factor receptor; T stage, tumor stage; N stage, node stage.

$\mathrm{P}=0.003$, respectively). Additionally, the risk of mortality was significantly increased in patients with high expression of c-Met or EGFR when compared with those with low expression $(\mathrm{HR}=6.976, \mathrm{P}=0.002 ; \mathrm{HR}=4.554, \mathrm{P}=0.016$, respectively). Among all the other factors, only lymph node metastasis increased the risk of disease recurrence (HR=3.246, $\mathrm{P}=0.016)$.

The multivariate Cox proportional hazards model analysis revealed that c-Met expression is an independent prognostic factor for DFS and OS $(\mathrm{HR}=4.050, \mathrm{P}=0.002 ; \mathrm{HR}=9.040$, $\mathrm{P}=0.008$, respectively; Tables III and IV). By contrast, EGFR was not observed to be an independent prognostic factor for DFS and $\mathrm{OS}(\mathrm{P}=0.352$ and $\mathrm{P}=0.240$, respectively). Histological grade was an independent prognostic factor for DFS and $\mathrm{N}$ stage had borderline significance $(\mathrm{HR}=0.376, \mathrm{P}=0.014$; $\mathrm{HR}=4.432, \mathrm{P}=0.051$, respectively; Table III).

Unlike results of c-Met, the assessment of the combined expression of c-Met and EGFR did not further improve prognostic capacity of c-Met for DFS and OS (likelihood ratio test,
$\mathrm{P}=0.119$ and $\mathrm{P}=0.160$, respectively; Table $\mathrm{V})$. These findings demonstrated that combined assessment of EGFR and c-Met expression did not have any more prognostic value superimposed effect in prognostic assessment.

\section{Discussion}

Tumor recurrence or metastasis following surgery is one of the main factors affecting prognosis (31). The known biomarkers of HNSCC, EGFR, cyclin D1, B-cell lymphoma 2, cyclin-dependent kinase inhibitor p27, vascular endothelial growth factor and p53 (32), are limited in their ability to predict prognosis, mainly due to the heterogeneity of cancers at different head and neck sites $(32,33)$. This is evident from the inconsistent studies on the association of EGFR and c-Met with prognosis of HNSCC (Table VI). The present study indicated that high expression of c-Met and EGFR significantly reduced DFS and OS. These findings indicated that abnormal expression of c-Met or EGFR proteins serve as potential biological markers 
Table V. Compared role of c-Met and combined assessment with both c-Met as well as EGFR for prognosis.

\begin{tabular}{|c|c|c|c|c|c|c|c|c|}
\hline \multirow[b]{2}{*}{ Expression } & \multicolumn{2}{|c|}{ HR $(95 \% \mathrm{CI})$} & \multicolumn{2}{|c|}{-2 Log likelihood } & \multicolumn{2}{|c|}{$\chi^{2}$} & \multicolumn{2}{|c|}{ P-value } \\
\hline & DFS & OS & DFS & OS & DFS & OS & DFS & OS \\
\hline c-Met & $4.785(2.239-10.225)$ & $6.976(2.026-24.026)$ & 277.754 & 135.494 & 2.426 & 1.978 & 0.119 & 0.160 \\
\hline \multicolumn{9}{|l|}{ Combination } \\
\hline c-Met & $3.816(1.695-8.592)$ & $4.941(1.330-18.360)$ & 275.328 & 133.516 & & & & \\
\hline EGFR & $1.832(0.832-4.032)$ & $2.372(0.644-8.740)$ & & & & & & \\
\hline
\end{tabular}

EGFR, epidermal growth factor receptor; HR, hazard ratio; CI, confidence interval; DFS, disease-free survival; OS, overall survival.

for GLSCC, and may have an improved predictive value when compared with clinicopathological factors.

EGFR is a member of the ErbB family, which promotes cell proliferation, invasion, metastasis and survival (5). Similar to findings from a previous study (34), the present study also revealed that $>90 \%$ of patients with GLSCC expressed EGFR protein. However, EGFR was not demonstrated to be an independent prognostic factor of DFS and OS. The present findings are in contrast to previous studies, which have observed that EGFR overexpression, increases risk of recurrence and mortality in patients with LSCC (35-37). The reason for such discrepancies in findings may be attributed to small sample size (38), difference in scoring methods and studies conducted on HNSCC rather than only GLSCC samples. Additionally, the present study was a retrospective one. Furthermore, a meta-analysis revealed that EGFR is most appropriate as an independent predictor of DFS in oropharyngeal carcinoma and not in laryngeal cancer (33). This indicated that EGFR may not be a suitable prognostic marker for all types of head and neck cancers. However, considering the aforementioned study limitations, it may be prudent to study this in a larger sample size in a prospective study.

c-Met, with a molecular weight of $190 \mathrm{kDa}$, consists of an extracellular $\alpha$-chain and transmembrane $\beta$-chain with tyrosine kinase activity (39). It has been observed that alterations of the c-Met gene in the form of amplification, deletion, mutation and overexpression are associated with tumor cell proliferation, migration, invasion and angiogenesis (40). Alterations of c-Met has been revealed to be associated with poor prognosis of numerous tumors, including breast, colorectal, liver, lung cancer and HNSCC $(20,41)$. However, such an association has not been studied specifically in GLSCC. The present study demonstrated an association between high expression of c-Met and recurrence and mortality of patients with GLSCC. It was also observed that high expression of c-Met is frequent in GLSCC, and was directly associated with the relapse, age and T-stage, which are factors linked with poor prognosis (42). Previous studies have revealed associations between c-Met expression and lymph node metastasis (16,43-45). Since the present study consisted of very few patients $(n=6)$ with nodal involvement, such an association could not be detected. It was observed that c-Met was an independent predictor of DFS and OS, which suggested that IHC evaluation of c-Met in primary tumors may contribute to identifying those patients with relapse and reduced chances of survival. Therefore, in the future, increased c-Met expression in patients with LSCC should be considered indicative of the requirement for good treatment modalities with consistent follow-up. In addition, univariate and multivariate analysis indicated that high expression of c-Met protein was significantly associated with a poorer prognosis when compared with that of EGFR protein. Thus, c-Met may perform a crucial function in the prognosis of LSCC; however, analysis in large numbers of LSCC samples is required.

c-Met and EGFR are frequently co-expressed in tumors, and act in synchrony to activate downstream signaling pathways, including Ras-Raf-extracellular signal-regulated kinase, signal transducer and activator of transcription 3 and phosphoinositide 3-kinase/Akt-mechanistic target of rapamycin cascades, to promote tumor progression (46). c-Met may be activated following EGFR activation, in the absence of HGF (47). c-Met activation by HGF was also shown to confer resistance to irreversible EGFR inhibitors $(48,49)$. The possible reason for this may be that the downstream signaling pathways maybe activated by c-Met, which is independent of EGFRs, leading to EGFR inhibitor-resistance (49). Benedettini et al (50) also demonstrated that lung cancer cells with low response to EGFR inhibitors, including gefitinib and erlotinib, exhibited high levels of c-Met. c-Met inhibitors may be used to circumvent the problem of drug-resistance to EGFR therapies (51). Thus, combined therapy with c-Met as well as EGFR inhibitors may improve the control of tumor cell proliferation (51). Based on these findings, the association between c-Met and EGFR was analyzed, and it was revealed that there was a significant positive association between c-Met and EGFR expression. In addition, subgroup analysis revealed that the DFS and OS times were extended within the subgroups of low EGFR and c-Met expression compared with at least one highly-expressed protein. However, combination of c-MET and EGFR did not provide more prognostic information, compared with c-MET alone for DFS and OS. This may be due to the fact that EGFR was not an independent prognostic factor of DFS and OS. Therefore, additional studies with a larger sample size are required to investigate the combined role of EGFR and c-Met.

To conclude, c-Met and EGFR are important predictors of survival in patients with GLSCC. Therefore, IHC analysis of primary tumors with the biological marker c-Met may provide greater potential to identify the prognosis. However, evaluation 


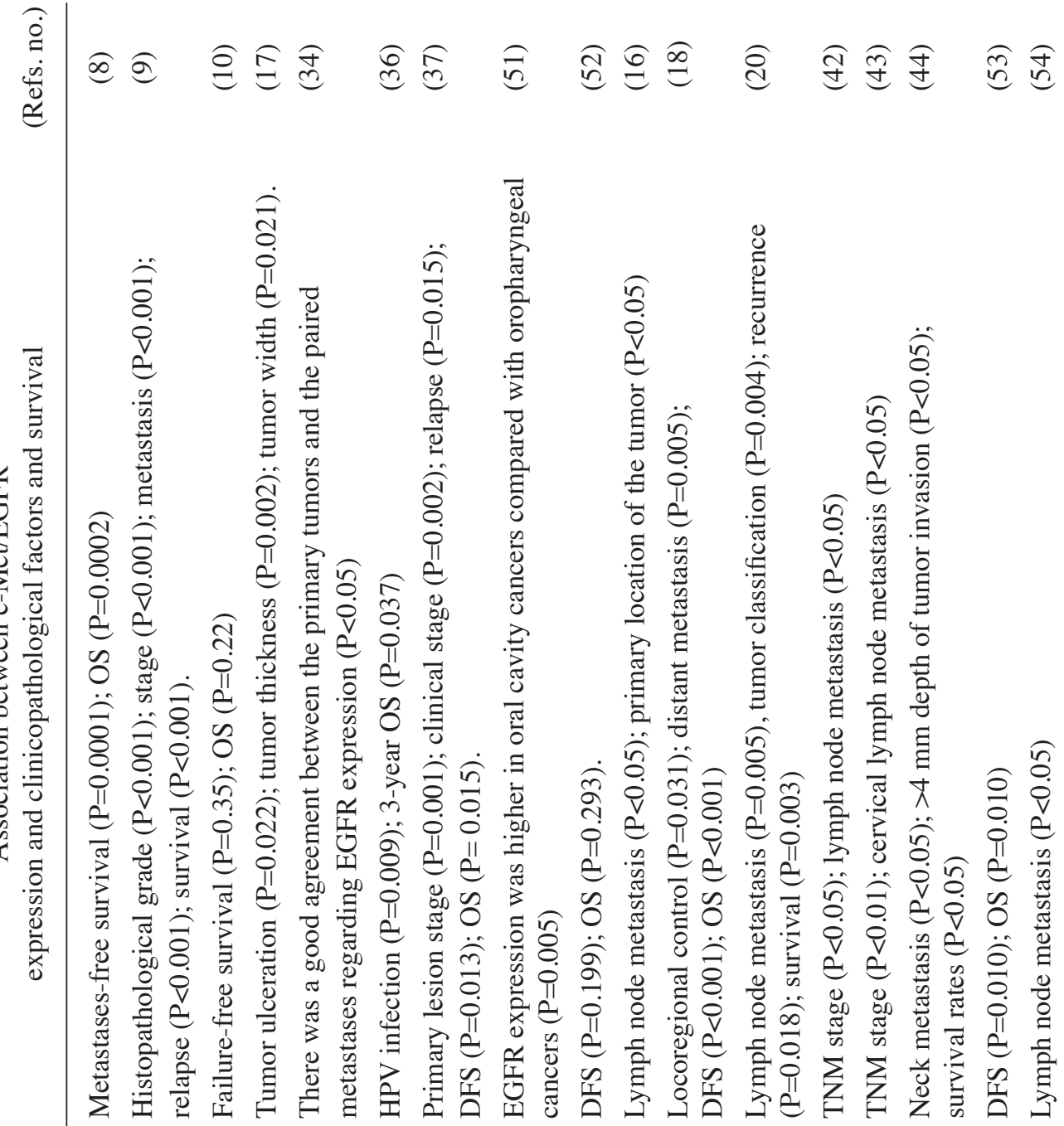

西

$\sum_{\substack{0 \\ 0}}^{2}$

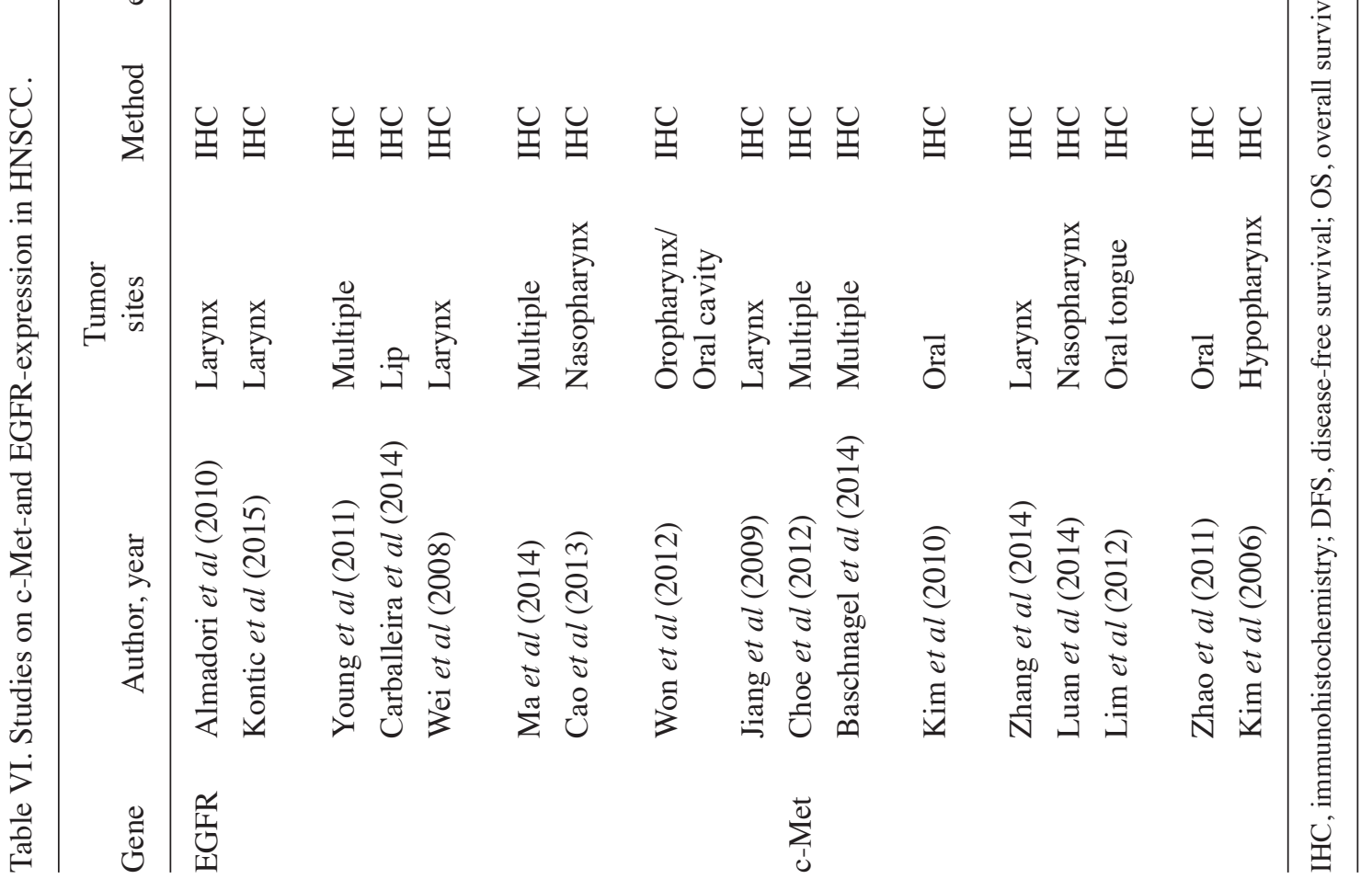

$\sqrt{2}$

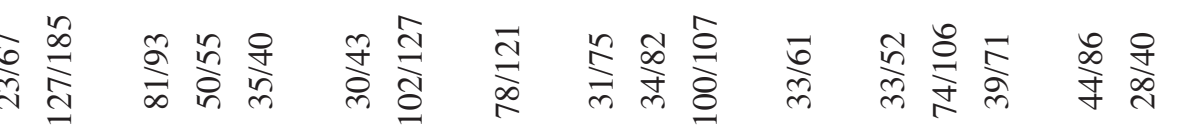


of c-Met and EGFR expression status should be performed on a larger sample population to obtain more reliable and consistent results. A more accurate prediction of outcomes with specific therapies, particularly molecular-targeted therapies, remains a worthy area of investigation.

\section{References}

1. Rudolph E, Dyckhoff G, Becher H, Dietz A and Ramroth H: Effects of tumour stage, comorbidity and therapy on survival of laryngeal cancer patients: A systematic review and a meta-analysis. Eur Arch Otorhinolaryngol 268: 165-179, 2011.

2. Chen W, Zheng R, Baade PD, Zhang S, Zeng H, Bray F, Jemal A, Yu XQ and He J: Cancer statistics in China, 2015. CA Cancer J Clin 66: 115-132, 2016,

3. Carvalho AL, Nishimoto IN, Califano JA and Kowalski LP: Trends in incidence and prognosis for head and neck cancer in the United States: A site-specific analysis of the SEER database. Int J Cancer 114: 806-816, 2005.

4. Zhang SY, Lu ZM, Luo XN, Chen LS, Ge PJ, Song XH, Chen SH and Wu YL: Retrospective analysis of prognostic factors in 205 patients with laryngeal squamous cell carcinoma who underwent surgical treatment. PLoS One 8: e60157, 2013.

5. Schlessinger J: Common and distinct elements in cellular signaling via EGF and FGF receptors. Science 306: 1506-1507, 2004.

6. Herchenhorn D and Ferreira CG: Targeting epidermal growth factor receptor to optimize chemoradiotherapy in locally advanced head and neck cancer: Has biology been taken into account. J Clin Oncol 29: e283-e287, 2011.

7. Specenier P and Vermorken JB: Cetuximab in the treatment of squamous cell carcinoma of the head and neck. Expert Rev Anticancer Ther 11: 511-524, 2011.

8. Almadori G, Bussu F, Gessi M, Ferrandina G, Scambia G, Lauriola L, Paludetti G and Ranelletti FO: Prognostic significance and clinical relevance of the expression of the HER family of type I receptor tyrosine kinases in human laryngeal squamous cell carcinoma. Eur J Cancer 46: 1144-1152, 2010.

9. Kontić M, Milovanović J, Čolović Z, Poljak NK, Šundov Ž, Sučić A and Pešutić-Pisac V: Epidermal growth factor receptor (EGFR) expression in patients with laryngeal squamous cell carcinoma. Eur Arch Otorhinolaryngol 272: 401-405, 2015.

10. Young RJ, Rischin D, Fisher R, McArthur GA, Fox SB, Peters LJ, Corry J, Lim A, Waldeck K and Solomon B: Relationship between epidermal growth factor receptor status, p16(INK4A), and outcome in head and neck squamous cell carcinoma. Cancer Epidemiol Biomarkers Prev 20: 1230-1237, 2011.

11. Maroun CR and Rowlands T: The Met receptor tyrosine kinase: A key player in oncogenesis and drug resistance. Pharmacol Ther 142: 316-338, 2014.

12. Graveel CR, Tolbert D and Vande Woude GF: MET: A critical player in tumorigenesis and therapeutic target. Cold Spring Harb Perspect Biol 5: pii: a009209, 2013.

13. Park S, Choi YL, Sung CO, An J, Seo J, Ahn MJ, Ahn JS, Park K, Shin YK, Erkin OC, et al: High MET copy number and MET overexpression: Poor outcome in non-small cell lung cancer patients. Histol Histopathol 27: 197-207, 2012.

14. Lee HE, Kim MA, Lee HS, Jung EJ, Yang HK, Lee BL, Bang YJ and Kim WH: MET in gastric carcinomas: Comparison between protein expression and gene copy number and impact on clinical outcome. Br J Cancer 107: 325-333, 2012.

15. Albiges L, Guegan J,Le Formal A, Verkarre V, Rioux-Leclercq N, Sibony M, Bernhard JC, Camparo P, Merabet Z, Molinie V, et al: MET is a potential target across all papillary renal cell carcinomas: Result from a large molecular study of pRCC with CGH array and matching gene expression array. Clin Cancer Res 20: 3411-3421, 2014.

16. Choe JY, Yun JY, Nam SJ and Kim JE: Expression of c-Met Is different along the location and associated with lymph node metastasis of head and neck carcinoma. Korean J Pathol 46: 515-522, 2012

17. Carballeira A, Ginarte M, Diniz-Freitas M, Fernández-Campos I, Gude F, Fraga M, Antúnez JR and García-Caballero T: Immunohistochemical evaluation of EGFR expression in lip squamous cell carcinoma. Correlation with clinicopathological characteristics. Histol Histopathol 29: 641-648, 2014.
18. Baschnagel AM, Williams L, Hanna A, Chen PY, Krauss DJ, Pruetz BL, Akervall J and Wilson GD: c-Met expression is a marker of poor prognosis in patients with locally advanced head and neck squamous cell carcinoma treated with chemoradiation. Int J Radiat Oncol Biol Phys 88: 701-707, 2014.

19. Ghadjar P, Blank-Liss W, Simcock M, Hegyi I, Beer KT, Moch H, Aebersold DM and Zimmer Y: MET Y1253D-activating point mutation and development of distant metastasis in advanced head and neck cancers. Clin Exp Metastasis 26: 809-815, 2009.

20. Kim CH, Koh YW, Han JH, Kim JW, Lee JS, Baek SJ, Hwang HS and Choi EC: c-Met expression as an indicator of survival outcome in patients with oral tongue carcinoma. Head Neck 32: 1655-1664, 2010.

21. Seiwert TY, Jagadeeswaran R, Faoro L, Janamanchi V, Nallasura V, El Dinali M, Yala S, Kanteti R, Cohen EE, Lingen MW, et al: The MET receptor tyrosine kinase is a potential novel therapeutic target for head and neck squamous cell carcinoma. Cancer Res 69: 3021-3031, 2009.

22. Luo J, Zha S, Gage WR, Dunn TA, Hicks JL, Bennett CJ, Ewing CM, Platz EA, Ferdinandusse S, Wanders RJ, et al: $\alpha$-methylacyl-CoA racemase: A new molecular marker for prostate cancer. Cancer Res 62: 2220-2226, 2002.

22. Sawatsubashi M, Sasatomi E, Mizokami H, Tokunaga O and Shin T: Expression of c-Met in laryngeal carcinoma. Virchows Arch 432: 331-335, 1998.

23. Bosch FX, Ritter D, Enders C, Flechtenmacher C, Abel U, Dietz A, Hergenhahn M and Weidauer H: Head and neck tumor sites differ in prevalence, and spectrum of p53 alterations but these have limited prognostic value. Int J Cancer 111: 530-538, 2004.

24. Götte K: Intratumoral genomic heterogeneity in head and neck cancer. Laryngorhinootologie 83: 122-123, 2004.

25. Betts GN, Eustace A, Patiar S, Valentine HR, Irlam J, Ramachandran A, Merve A, Homer JJ, Möller-Levet C, Buffa FM, et al: Prospective technical validation and assessment of intra-tumour heterogeneity of a low density array hypoxia gene profile in head and neck squamous cell carcinoma. Eur J Cancer 49: 156-65, 2013.

26. Moertel S, Ackermann H, Baghi M, Eckardt A, Wagenblast J, Stöver T and Hambek M: Heterogeneity of primary site biopsies in head and neck squamous cell carcinoma. Anticancer Res 31: 665-669, 2011,

27. Greene FL, Page DL, Fleming ID (eds), et al: AJCC Cancer Staging Manual. 6th edition. New York, NY, Springer, 2002.

28. Carlsson J, Nordgren H, Sjöström J, Wester K, Villman K, Bengtsson NO, Ostenstad B, Lundqvist $\mathrm{H}$ and Blomqvist $\mathrm{C}$ : HER 2 expression in breast cancer primary tumours and corresponding metastases. Original data and literature review. Br J Cancer 90: 2344-2348, 2004.

28. Kim CH, Moon SK, Bae JH, Lee JH, Han JH, Kim K and Choi EC: Expression of hepatocyte growth factor and c-Met in hypopharyngeal squamous cell carcinoma. Acta Otolaryngol 126: 88-94, 2006.

29. Patel M, Lu L, Zander DS, Sreerama L, Coco D and Moreb JS: ALDH1A1 and ALDH3A1 expression in lung cancers: Correlation with histologic type and potential precursors. Lung Cancer 59: 340-349, 2008.

30. Mazières J, Brugger W, Cappuzzo F, Middel P, Frosch A, Bara I, Klingelschmitt $\mathrm{G}$ and Klughammer B: Evaluation of EGFR protein expression by immunohistochemistry using $\mathrm{H}$-score and the magnification rule: Re-analysis of the SATURN study. Lung Cancer 82: 231-237, 2013.

31. Schaaij-Visser TB, Brakenhoff RH, Leemans CR, Heck AJ and Slijper M: Protein biomarker discovery for head and neck cancer. J Proteomics 73: 1790-1803, 2010.

32. Kim KY, Mcshane LM and Conley BA: Designing biomarker studies for head and neck cancer. Head Neck 36: 1069-1075, 2014,

33. Keren S, Shoude Z, Lu Z and Beibei Y: Role of EGFR as a prognostic factor for survival in head and neck cancer: A meta-analysis. Tumor Biol 35: 2285-2295, 2014.

34. Wei Q, Sheng L, Shui Y, Hu Q, Nordgren H and Carlsson J: EGFR, HER2, and HER3 expression in laryngeal primary tumors and corresponding metastases. Ann Surg Oncol 15: 1193-1201, 2008.

35. Farhadieh RD, Salardini A, Rees CG, Russell PJ, Yang JL and Smee R: Protein expression of epidermal growth factor receptor in laryngeal squamous cell carcinoma index tumors correlates with diagnosis of second primary tumors of the upper aero-digestive tract. Ann Surg Oncol 16: 2888-2894, 2009. 
36. Ma L, Wang D, Wufuer A, Wu R, Zhang $\mathrm{S}$ and Wang $\mathrm{R}$ Relationship between human papilloma virus infection and expression of p16 and EGFR in head and neck squamous cell carcinoma and their prognostic significance. Zhonghua Zhong Liu Za Zhi 36: 23-28, 2014 (In Chinese).

37. Cao XJ, Hao JF, Yang XH, Xie P, Liu LP, Yao CP and Xu J: Prognostic value of expression of EGFR and $\mathrm{nm} 23$ for locoregionally advanced nasopharyngeal carcinoma. Med Oncol 29 263-271, 2012.

38. Marioni G, Blandamura S, Loreggian L, Koussis H, Lionello M, Giacomelli L, Fasanaro E, Lovato A and Staffieri A: Laryngeal carcinoma prognosis after postoperative radiotherapy correlates with CD105 expression, but not with angiogenin or EGFR expression. Eur Arch Otorhinolaryngol 268: 1779-1787, 2011.

39. Bhardwaj V, Cascone T, Cortez MA, Amini A, Evans J, Komaki RU, Heymach JV and Welsh JW: Modulation of c-Met signaling and cellular sensitivity to radiation: Potential implications for therapy. Cancer 119: 1768-1775, 2013.

40. Han CB, Ma JT, Li F, Zhao JZ, Jing W, Zhou Y and Zou HW: EGFR and KRAS mutations and altered c-Met gene copy numbers in primary non-small cell lung cancer and associated stage N2 lymph node-metastasis. Cancer Lett 314: 63-72, 2012.

41. Goetsch L, Caussanel V and Corvaia N: Biological significance and targeting of c-Met tyrosine kinase receptor in cancer. Front Biosci (Landmark Ed) 18: 454-473, 2013.

42. Zhang Y,Zhao J and Zhang Q: The expression and clinical significance of OPN and C-met in laryngeal carcinoma. Lin Chung Er B Yan Hou Tou Jing Wai Ke Za Zhi 28: 256-258, 2014 (In Chinese).

43. Luan T and Yu Y: Increased hepatocyte growth factor and c-Met receptor expression in nasopharyngeal carcinoma. Int J Clin Exp Med 7: 5583-5587, 2014.

44. Lim YC, Han JH, Kang HJ, Kim YS, Lee BH, Choi EC and Kim CH: Overexpression of c-Met promotes invasion and metastasis of small oral tongue carcinoma. Oral Oncol 48: 1114-1119, 2012.
45. Zhao D, Wang SH, Feng Y, Hua CG, Zhao J and Tang XF: Intratumoral c-Met expression is associated with vascular endothelial growth factor $\mathrm{C}$ expression, lymphangiogenesis, and lymph node metastasis in oral squamous cell carcinoma: Implications for use as a prognostic marker. Hum Pathol 42: 1514-1523, 2011.

46. Ishibe S, Karihaloo A, Ma H, Zhang J, Marlier A, Mitobe M, Togawa A, Schmitt R, Czyczk J, Kashgarian M, et al: Met and the epidermal growth factor receptor act cooperatively to regulate final nephron number and maintain collecting duct morphology. Development 136: 337-345, 2009.

47. Saunders VC, Lafitte M, Adrados I, Quereda V, Feurstein D, Ling Y, Fallahi M, Rosenberg LH and Duckett DR: Identification of an EGFRvIII-JNK2-HGF/c-Met-signaling axis required for intercellular crosstalk and glioblastoma multiforme cell invasion. Mol Pharmacol 88: 962-969, 2015.

48. Puri N and Salgia R: Synergism of EGFR and c-Met pathways, cross-talk and inhibition, in non-small cell lung cancer. J Carcinog 7: 9, 2008

49. Yamada T, Matsumoto K, Wang W, Li Q, Nishioka Y, Sekido Y, Sone S and Yano S: Hepatocyte growth factor reduces susceptibility to an irreversible epidermal growth factor receptor inhibitor in EGFR-T790M mutant lung cancer. Clin Cancer Res 16: 174-183, 2010.

50. Benedettini E, Sholl LM, Peyton M, Reilly J, Ware C, Davis L, Vena N, Bailey D, Yeap BY, Fiorentino M, et al: Met activation in non-small cell lung cancer is associated with de novo resistance to EGFR inhibitors and the development of brain metastasis. Am J Pathol 177: 415-423, 2010.

51. Lau PC and Chan AT: Novel therapeutic target for head and neck squamous cell carcinoma: HGF-MET signaling pathway. Anticancer Drugs 22: 665-673, 2011. 